\title{
A distributive method to increase the analogic output (D/A) resolution of a microcomputer
}

\author{
L. DIONNE, L. LAURENCELLE, and F. TREMBLAY \\ Université du Québec à Trois-Rivières, Trois-Rivières, Québec, Canada
}

\begin{abstract}
This paper describes a simple and efficient method to increase the D/A output resolution of an 8-bit microcomputer, as exemplified on the Apple II. The "distributive method" can increase the final output resolution up to $32 \mathrm{~K}$ with two 8-bit analogic channels. A simple interface based on balanced sets of resistors and driver software are described. Some applications are also reported.
\end{abstract}

Computers are indispensable tools in the modern laboratory, especially for electrophysiology studies in which computers are used to collect large amounts of data and to generate a variety of stimulations with ease, rapidity, and efficiency. The first generation of microcomputers congruous with bioscience laboratories was in the 8-bit class (e.g., the Apple II or its versions and copies), and they were built to meet a wide range of applications. These computers still do their job quite well, but their usefulness in particular applications is somewhat impeded by the 8-bit limitation. For example, neurologists and neurophysiologists may need to collect, cumulate, and view electrophysiological signals recorded with sufficient precision. The coarseness of the display based on a 256-step scale is often annoying. The same limitation appears when one wants to generate a graphic pattern, linear or otherwise, on an analogic screen. The analogic output of the Apple II, normally implemented with 8 bits, has a definition that is aesthetically and sometimes critically insufficient and that needs improvement.

Of the many alternatives for circumventing the problem, the one described here involves dispatching a 9- to 16-bit word of definition over two 8-bit channels. This is brought about by making a minor hardware modification to a multichannel 8-bit D/A converter and by writing a short driver routine in assembler language. We propose this as a fair solution, particularly in the short term, for improving the resolution of the analogic output of a microcomputer; it also can serve to pretest application programs before transferring them to a bigger computer, if the need still exists to do so.

\section{WORKING PRINCIPLE}

Each channel of an 8-bit D/A card can provide $256 \mathrm{vol}-$ tage increments distributed, for example, on a $-5 \mathrm{~V}$, $+5 \mathrm{~V}$ range. A natural way to increase this precision is to add voltage levels by joining two channels, making up a 16-bit data word. The first channel (low-byte channel)

Address correspondence to Louis Dionne, Groupe de recherche en Neuropsychologie, Université due Québec à Trois-Rivières, C.P. 500, Trois-Rivières, Québec G9A 5H7, Canada. will be used to transmit the lower 7 bits of information, running progressively over the positive part of its range $(0 \mathrm{~V},+5 \mathrm{~V})$ through 128 increments. The second channel (high-byte channel) operates as a multiplier and determines the overall range. Each increment produces a voltage that is equivalent to the total output range of the lower channel (refer to Figure 1). This is brought about by using resistors that adjust the voltage range of the two channels in the proper ratio, and then by adding the two outputs.

For example, suppose one needs a $1 \mathrm{~K}$ resolution, or 1024 gradations, for the analogic output of an Apple II. First, one must build an interface for combining properly two channels of an 8-bit D/A card. To obtain $1 \mathrm{~K}$ of resolution, the lower channel is used to produce the 128 finer levels of voltage, which in turn must be stepped up 8 times through the high-byte channel in order to produce the desired number of levels $(128 \times 8=1024)$. The high-byte channel output must then be divided into 8 levels of $1,25 \mathrm{~V}$ each. The overall range, for instance, would be $10 \mathrm{~V}$, and the 8-level variation would be programmed in the 3 higher bits, 5-7, of the high-byte channel. By using appropriate resistors, the $(0 \mathrm{~V},+5 \mathrm{~V})$ variation on the low-byte channel can be reduced to a $0 \mathrm{~V},+1,25 \mathrm{~V}$ range; the two voltage outputs can then be mixed. One then inserts in the main program a short routine handling the numeric dispatching and D/A triggering. An output with $1 \mathrm{~K}$ levels, ranging from $-5 \mathrm{~V}$ to $+5 \mathrm{~V}$, has thus been created by "distributing" a 10-bit value over two 8-bit D/A channels.

\section{Hardware}

The hardware part of this system is simple to build and requires common parts easily found in electronic stores. The attenuators must follow a ratio given by the formula $A_{H} / A_{L}=\operatorname{Res} / 128$, where $A_{H}$ and $A_{L}$ represent the attenuator values associated with the high- and low-byte channels, respectively, and Res is the total resolution needed. The value 128 is the number of levels produced in the low-byte channel; the expected quotient Res/256 is multiplied by 2 because the low-byte channel uses only half the total range of voltage $(0,+5 \mathrm{~V})$ of the high-byte channel. Whatever the value of this ratio, the resistors may 
CHANNEL I

LOW BYTE
CHANNEL 2

HIGH BYTE

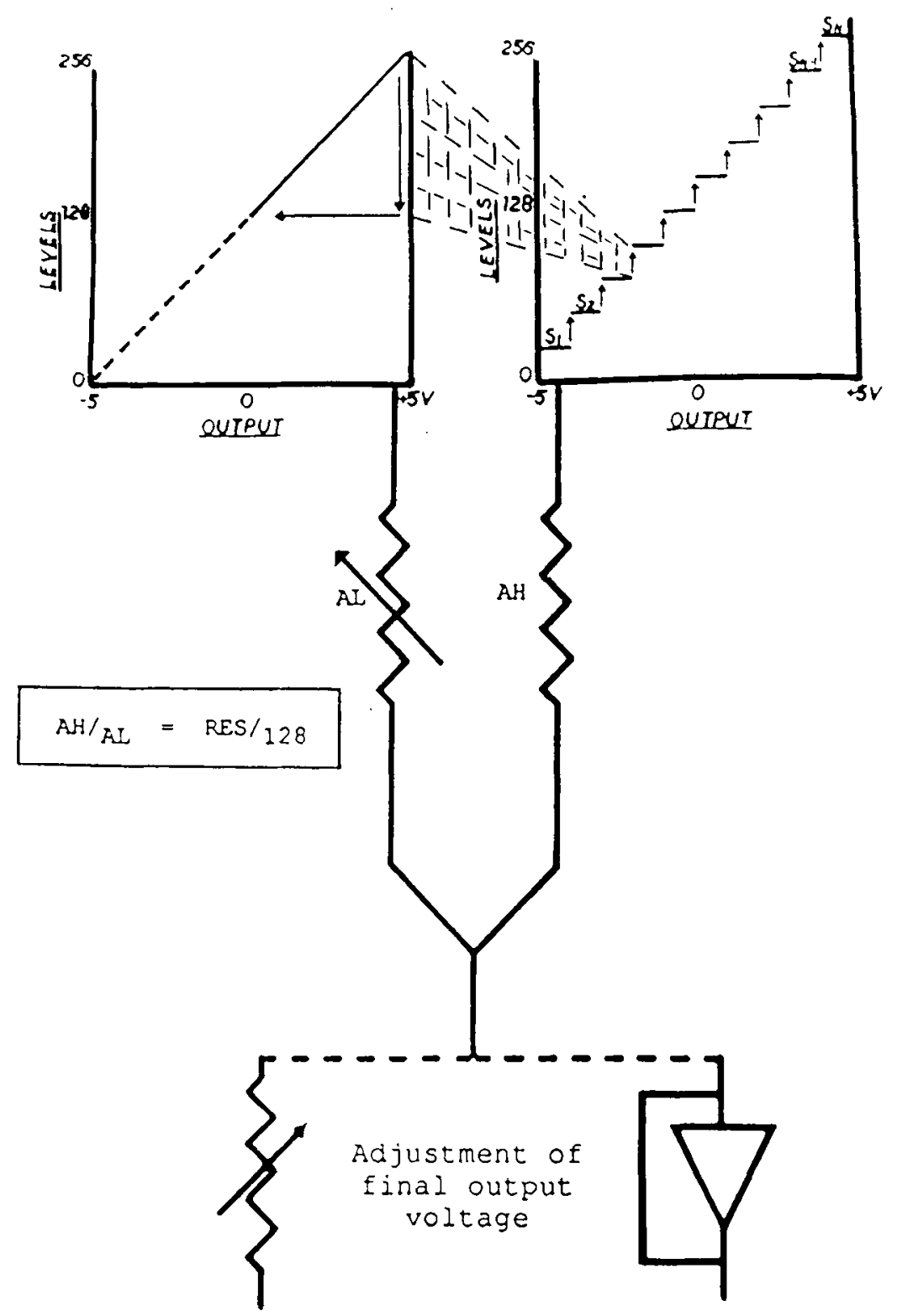

Figure 1. Working principle of the distributive method. Two channels of the D/A converter are used in conjunction to simulate a continuous output ranging between $128 \mathrm{~K}$ and 32K of final resolution, depending on the number of steps one creates in the high-byte channel ( $S_{N}$; right graph). The low-byte channel varies from 128 to $255(0-5 \mathrm{~V})$, looping inside each step of the higher channel. (That correspondence is shown by the shadowed surface.) These two outputs pass through two resistors and are then mixed to produce a higher resolution output within a $-5 \mathrm{~V}$ to $+5 \mathrm{~V}$ range. See Figure 2 for details of the electronic circuit.

be in the range from $1 \mathrm{k} \Omega$ to $100 \mathrm{k} \Omega$ to comply with most peripheral equipment.

The user should buy resistors with the finest tolerance available. In fact, it is still better to couple a resistor of fixed value with a potentiometer, which could compensate for the tolerance error. Moreover, with a potentiometer it is possible to alter the ratio, and, if minor changes are made in the software, the user can quite easily increase or decrease the final resolution of his system.

\section{Software}

Listing 1 shows an assembler routine for the 6502 processor that fits the example developed in the preceding section. Executing this routine will produce a signal 


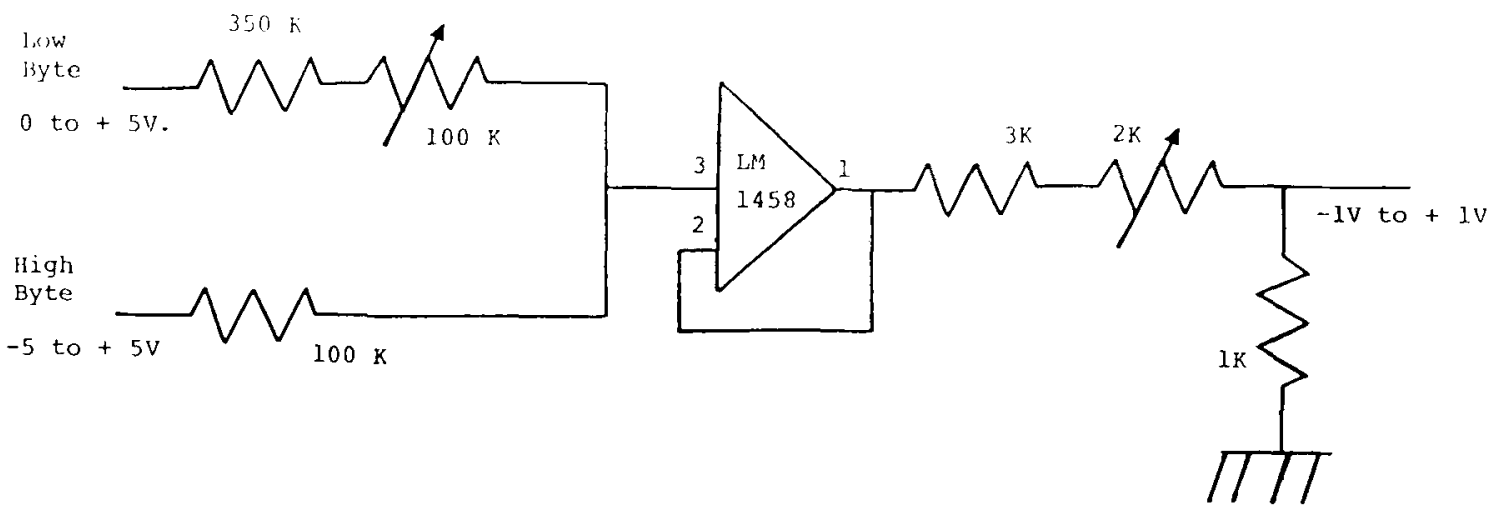

Figure 2. Details of the electronic circuit needed to produce an output of $-1 \mathrm{~V}$ to $+1 \mathrm{~V}$ from an input of $-5 \mathrm{~V}$ to $+5 \mathrm{~V}$ with a resolution of 1024 . The first potentiometer $(100 \mathrm{k} \Omega)$ permits a fine adjustment for $A H: A L$ ratio, and the second $(2 \mathrm{k} \Omega)$ allows for the positioning of the final output level.

on an $X-Y$-Z oscilloscope; the horizontal definition is 1024 points while the vertical is kept at 256 points. The distribution parameters can be found between lines 16 and 19. Lines 23-28 fix initial values for controlling the output channels $\left(X_{L}=128 ; X_{H}=0 ; Y=0\right)$. Lines $29-48$ include instructions defining two loops: the inner one increments the lower channel from 128 to 255 , while the outer loop adds an increment of value 32 , or $256 / 8$, in the higher channel. If the card used entails a delay covering conversion time, the user should insert as many $<$ nop $>$ instructions as are needed at appropriate locations in the program. (Note that each $\langle$ nop $\rangle$ burns out $2 \mu \mathrm{sec}$.)

Such an assembler routine is requisite when the signal is to be displayed (and regenerated) on an analogic oscil- loscope, whose remanence is low. On the other hand, an equivalent BASIC program, for instance in Applesoft, runs conveniently to drive an analogic $X-Y$ plotter for producing a hard copy of the graphic. Such a program, outlined in Listing 2, corresponds to the preceding one and thus requires no further comment.

\section{DOMAINS OF APPLICATION}

The concept of this method, which we call "distributive," can be used in a variety of applications, each time the analogic output capacity of a microcomputer is involved. We have developed and tested this method by including it in software that averages evoked EEG poten-

Listing 1

Example of a 6502 Routine to Obtain 1K of Resolution with the <DISTRIBUTIVE > Method

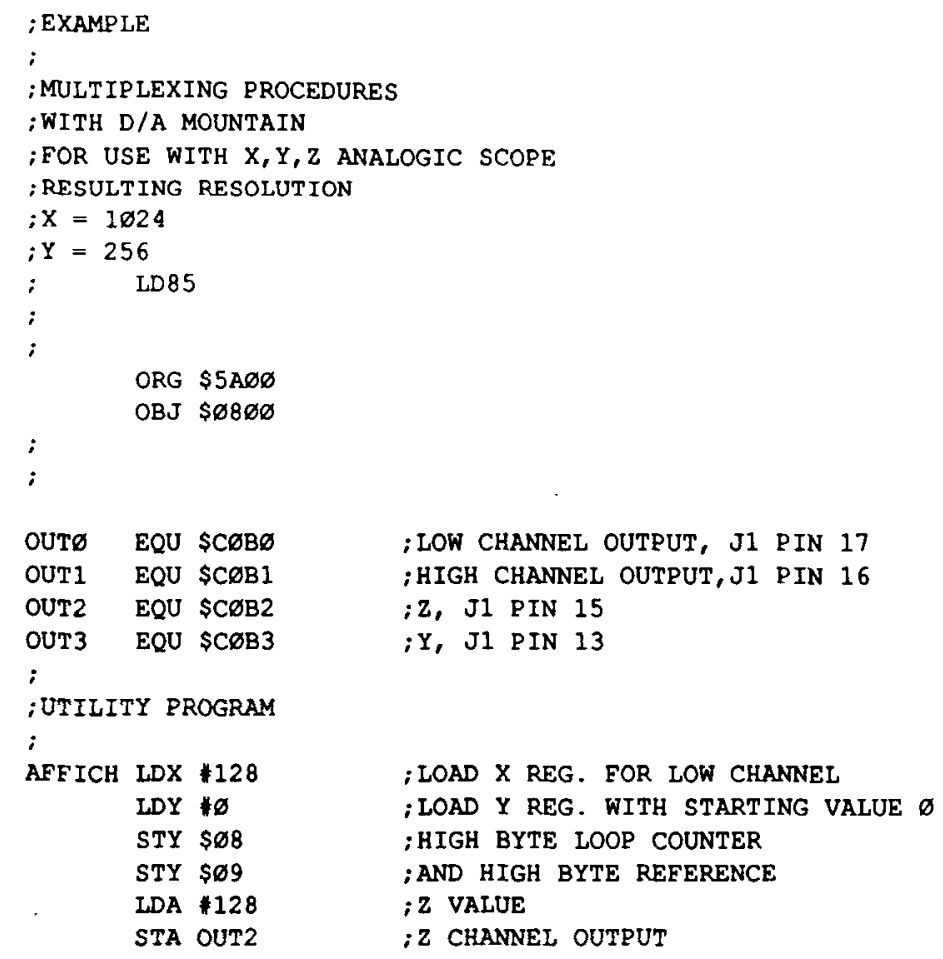

; LOAD X REG. FOR LOW CHANNEL ; LOAD Y REG. WITH STARTING VALUE $\emptyset$ ; HIGH BYTE LOOP COUNTER ;AND HIGH BYTE REFERENCE ; 2 VALUE iZ CHANNEL OUTPUT 
Listing 1 (Continued)

\begin{tabular}{|c|c|c|c|c|c|}
\hline $\begin{array}{l}890060 \\
E A\end{array}$ & $\begin{array}{l}29 \\
30\end{array}$ & AFF & $\begin{array}{l}\text { LDA } \\
\text { NOP }\end{array}$ & $\$ 6000, Y$ & $\begin{array}{l}\text {; BANK BUFFER, ENTERING IN MASTER LOOP } \\
\text {;WASTE TIME (OPTIONAL) }\end{array}$ \\
\hline $8 E B \varnothing C \varnothing$ & 31 & & STX & OUTø & ; $X$ LOW (LOW CHANNEL) OUTPUT \\
\hline 8DB3CD & 32 & & STA & OUT3 & ; Y CHANNEL OUTPUT \\
\hline E8 & 33 & & INX & & ;NEXT BIN \\
\hline DøळE & 34 & & BNE & NEXTY & ; IF NOT $\oslash$ STAY IN EIRST STEP OF HIGH BYTE \\
\hline A28ø & 35 & & LDX & $\$ 128$ & ; LOAD X REG FOR LOW CHANNEL VALUE \\
\hline A509 & 36 & & LDA & $\$ \varnothing 9$ & ; HIGH BYTE REFERENCE \\
\hline 6920 & 37 & & $\mathrm{ADC}$ & $\# 32$ & ;NEXT STEP IN HIGH BYTE \\
\hline 8509 & 38 & & STA & $\# \varnothing 9$ & ;PROTECT NEW REFERENCE \\
\hline 8DB1CD & 39 & & STA & OUT 1 & ;OUTPUT NEW HIGH BYTE VALUE \\
\hline $4 C 315 A$ & 40 & & JMP & ICI & \\
\hline $\mathrm{C} 8$ & 41 & NEXTY & INY & & ;NEXT BYTE IN BANK BUFFER \\
\hline $\mathrm{D} \varnothing \mathrm{E} 2$ & 42 & & BNE & AFF & :TO MASTER LOOP \\
\hline EEØF5A & 43 & & INC & $\mathrm{AFF}+2$ & ; ADD 256 TO BANK BUEFER POINTER \\
\hline $4 \operatorname{COD} 5 A$ & 44 & & JMP & $\mathrm{AFF}$ & :TO MASTER LOOP \\
\hline $\mathrm{E} 608$ & 45 & ICI & INC & $\$ 98$ & ; INCREMENT HIGH BYTE LOOP COUNTER \\
\hline A 568 & 46 & & LDA & $\$ \varnothing 8$ & ; AND CHECK \\
\hline C908 & 47 & & CMP & $\# 08$ & ; IF LAST PASS \\
\hline DQEE & 48 & & BNE & NEXTY & ; IF NOT \\
\hline \multirow[t]{4}{*}{60} & 49 & ; & RTS & & \\
\hline & 50 & ; & UTII & UITY PROGRAM & \\
\hline & 51 & ; & & & \\
\hline & 52 & & END & & \\
\hline
\end{tabular}

Listing 2

BASIC Version of the Same Routine

\begin{tabular}{|c|c|c|c|c|}
\hline 1000 & $V I=24576$ & : & REM & FIRST VALUE IN MEMORY \\
\hline 1010 & 49341 & : & REM & LOW CHANNEL OUTPUT CHANNEL 13, PIN 3 \\
\hline 1020 & 49342 & : & REM & HIGH CHANNEL OUTPUT CHANNEL 14, PIN 2 \\
\hline 1030 & 49343 & : & REM & CHANNEL 15, PIN 1 \\
\hline 1040 & 49340 & : & REM & PEN LIFT CONTROL \\
\hline 1050 & POKE PL, 255 & : & REM & PEN UP \\
\hline 1060 & POKE XB, 128 & : & REM & LOAD $X$ AXIS FOR LOW CHANNNEL WITH O \\
\hline 1070 & POKE XH, 0 . & : & REM & LOAD X AXIS HIGHT CHANNEL WITH $-5 \mathrm{~V}$ \\
\hline 1080 & POLE YD, 128 & : & REM & MIDRANGE VALUE FOR Y AXIS \\
\hline 1090 & GET AS & : & REM & SET YOUR PRINTER AND GO \\
\hline 1100 & POKE PL, 0 & : & REM & PEN DOWN \\
\hline 1110 & FOR $I=0 \mathrm{TO}$ & 224 & STEP & $32:$ REM LOOP FOR HIGHER BYTE \\
\hline 1120 & FOR $B=128 \mathrm{I}$ & TO 25 & 55 & : REM LOOP FOR LOWER BYTE \\
\hline 1130 & $Y=Y+1$ & $:$ & REM C & COUNTER \\
\hline 1140 & $D Y=P E E K \quad(V I$ & $I+y$ & Y) & : REM VALUE IN MEMORY \\
\hline 1150 & POKE XB, B : & POKE & KE XH, & $\begin{array}{c}\text { I : REM SELECT THE CORRECT BIN } \\
(X \text { AXIS })\end{array}$ \\
\hline 1160 & POKE YD, DY & : & REM & PLACE THE VALUE IN CHANNEL $Y$ \\
\hline 1170 & NEXT B & : & REM & IF $B=>255$ THEN RESET AND $\ldots$ \\
\hline 1180 & NEXT I & $:$ & REM & $\begin{array}{l}\text { ADD } 32 \text { UNITS (TO OBTAIN I K) } \\
\text { IN HIGHER BYTE }\end{array}$ \\
\hline 1190 & POKE PL, 255 & : & REM & \\
\hline 1200 & STOP & & & \\
\hline
\end{tabular}


tials. Besides increasing the quality of the visual output, particularly on a large screen, the system makes it possible to scrutinize a small portion of the curve directly on the screen without having to edit the signal, expand the display, or otherwise complicate the signal processing software. Also, when plotted on the $X-Y$ recorder, the curve appears smoother, without a staircase effect often seen in hard-copy illustrations; it looks as if it were continuous.

The distributive method may also be useful for displaying histograms or other kinds of graphs, by increasing the resolution of the $X$ (or time) axis. In comparison with histograms obtained with an 8-bit D/A card, it becomes feasible to display more bars so that a higher resolution is obtained by reducing the bin-width, or alternatively a signal of longer duration by keeping the bin-width and adding more bins.

The method has also been adapted to an apparatus that controls moving parts, such as a (continuous) motor. Through an increase in the resolution, all movements be- come smoother, without basklash due to coarse settling, thus reducing wearing down of moving parts and obviating in some cases the need for a feedback-controlled positioning.

\section{CONCLUSION}

The possibilities for using the distributive method are numerous. The concept and the application of the system are quite simple, and it allows the use of available or cheap microcomputer equipment for applications requiring a performance typical of costlier or unavailable hardware. The user is also able to take advantage of the availability of well-known programs with an Apple II, instead of having to start anew with a more sophisticated, but more complicated, hardware and with nonexistent or unproven software.

(Manuscript received January 30, 1987; revision accepted for publication June 15,1987 .) 